\title{
Plasma Levels of Adrenomedullin and Atrial and Brain Natriuretic Peptides in the General Population: Their Relations to Age and Pulse Pressure
}

\author{
Johji KATO, Kazuo KITAMURA, Tomohiko UEMURA, Kenji KUWASAKO, Toshihiro KITA, \\ Kenji KANGAWA* , and Tanenao ETO
}

\begin{abstract}
Adrenomedullin (AM) and atrial and brain natriuretic peptides (ANP and BNP) exert vasodilator and natriuretic actions and are thought to share roles in counteracting the progression of hypertension or heart failure as circulating or locally-acting hormones. However, little data is available with regard to their roles in subjects who have no apparent cardiovascular diseases. The present study was carried out to identify the factors that affect plasma levels of AM, ANP and BNP in the general population. We measured the plasma levels of AM, ANP and BNP in 184 local residents who had a scheduled regular health checkup, and compared the findings with those for other clinical parameters. Univariate analyses showed that the plasma levels of AM, ANP and BNP were significantly correlated with age. The plasma levels of ANP and BNP were also significantly correlated with systolic blood pressure (SBP) and with pulse pressure (PP), an indicator of the stiffness of the great vessels. Multivariate analyses conducted using a stepwise method revealed that age was a significant, independent variable for the plasma levels of AM, ANP and BNP. In addition, PP was a significant factor for the plasma levels of ANP and BNP, while the plasma AM was significantly associated with body mass index (BMI). Thus, the plasma levels of AM, ANP and BNP all increased in association with aging, and those of ANP and BNP increased in association with PP, suggesting possible relationships between the plasma levels and age-related changes in the cardiovascular system. (Hypertens Res 2002; 25: 887-892)
\end{abstract}

Key Words: adrenomedullin, atrial natriuretic peptide, brain natriuretic peptide, age, pulse pressure

\section{Introduction}

Adrenomedullin (AM) is a potent vasodilator peptide initially identified in human pheochromocytoma tissue (1). In addition to vasodilation, this peptide shows a wide spectrum of biological activities, including natriuresis, inhibition of aldosterone secretion, stimulation of nitric oxide (NO) production and inhibition of cardiomyocyte hypertrophy $(2,3)$. Both AM gene expression and AM peptide have been detected in the adrenal medulla, kidney, aorta, and cardiac atrium and ventricle, and AM has been found in human blood $(2,3)$. Atrial and brain natriuretic peptides (ANP and BNP) are cardiac hormones having natriuretic and vasodilator actions (4, 5). In humans, these two natriuretic peptides are secreted from the cardiac atrium or ventricle, and are also present in the bloodstream $(4,5)$. Plasma concentrations of AM, ANP and BNP are similarly elevated in patients with hypertension or congestive heart failure compared with control subjects, and these elevated plasma concentrations have been shown to be reduced by successful treatment in these patients (2-5). These findings, together with the vasodilator and natriuretic

From the First Department of Internal Medicine, Miyazaki Medical College, Miyazaki, Japan, and * Department of Biochemistry, National Cardiovascular Center Research Institute, Suita, Japan.

This study was supported in part by Grants-in-Aid for Scientific Research from the Ministry of Education, Culture, Sports, Science and Technology in Japan. Address for Reprints: Johji Kato, M.D., First Department of Internal Medicine, 5200 Kihara, Kiyotake, Miyazaki 889-1692, Japan.

E-mail: JKJPN@post.miyazaki-med.ac.jp

Received May 22, 2002; Accepted in revised form August 20, 2002. 
Table 1. Basal Profiles of Subjects

\begin{tabular}{lc}
\hline Male/female $(n)$ & $63 / 121$ \\
Age $($ year $)$ & $56.3 \pm 10.7$ \\
SBP $(\mathrm{mmHg})$ & $127.1 \pm 17.6$ \\
$\mathrm{DBP}(\mathrm{mmHg})$ & $77.6 \pm 10.5$ \\
$\quad \mathrm{SBP} / \mathrm{DBP} \geqq 140 / 90(\%)$ & 30 \\
$\mathrm{PP}(\mathrm{mmHg})$ & $49.5 \pm 14.5$ \\
$\mathrm{BMI}\left(\mathrm{kg} / \mathrm{m}^{2}\right)$ & $23.13 \pm 3.18$ \\
$\mathrm{BMI} \geqq 25 \mathrm{~kg} / \mathrm{m}^{2}(\%)$ & 29 \\
Creatinine $(\mathrm{mg} / \mathrm{dl})$ & $0.61 \pm 0.14$ \\
Total cholesterol $(\mathrm{mg} / \mathrm{dl})$ & $193.4 \pm 34.3$ \\
$\quad$ Total cholesterol $222 \mathrm{mg} / \mathrm{dl}(\%)$ & 17 \\
\hline
\end{tabular}

SBP and DBP, systolic and diastolic blood pressure; PP, pulse pressure; BMI, body mass index. Mean \pm SD.

actions of these hypotensive peptides, suggest that AM, $\mathrm{ANP}$, and BNP participate in a mechanism acting against further progression of hypertension or heart failure (2-6). However, there is limited information about their roles in subjects without overt cardiovascular diseases. In the present study, we measured the plasma levels of AM, ANP and BNP in local residents receiving a regular health checkup, and compared the findings with other clinical parameters in order to identify the factors affecting the plasma levels of these blood pressure-lowering peptides in the general population.

\section{Methods}

\section{Subjects and Blood Sampling}

Local residents in the Kiyotake region of Miyazaki, Japan who received regular annual health checkups were selected for this study (63 males and 121 females; mean age \pm SD, 56.3 \pm 10.7 years). None of the subjects had any overt cardiovascular diseases, such as ischemic heart disease, congestive heart failure or atherosclerotic vascular disease, based on their medical history and physical examination. Subjects with diabetes mellitus were excluded. Blood pressure was measured by a sphygmomanometer with subjects in a seated position, and then blood was drawn from an antecubital vein. Serum total cholesterol and creatinine levels were determined by enzymatic methods. To measure the plasma concentrations of AM, ANP and BNP, blood was collected in tubes with $1.0 \mathrm{mg} / \mathrm{ml}$ of EDTA-2Na and 500 kallikrein inhibitory units $(\mathrm{KIU}) / \mathrm{ml}$ of aprotinin. Plasma was obtained by centrifugation at 3,000 rpm for $10 \mathrm{~min}$ at $4^{\circ} \mathrm{C}$ and stored at $-40^{\circ} \mathrm{C}$ until assayed. This study was approved by the Review Committee of the Cooperative and Commissioned Research of Miyazaki Medical College, and all subjects gave their informed consent to participate.

\section{Assay Procedures}

The plasma AM concentrations were measured with a spe- cific radioimmunoassay (RIA) following the extraction of plasma as described previously $(7,8)$. In brief, $2 \mathrm{ml}$ of plasma was loaded onto a Sep-Pak C18 cartridge (Millipore-Waters, Milford, USA) equilibrated with $5 \mathrm{ml}$ of saline. After the cartridge was washed with $5 \mathrm{ml}$ of saline and $10 \%$ acetonitrile in $0.1 \%$ trifluoroacetic acid (TFA), the absorbed material was eluted with $4 \mathrm{ml}$ of $60 \%$ acetonitrile in $0.1 \%$ TFA and lyophilized, then stored at $-40{ }^{\circ} \mathrm{C}$ until assayed. The plasma extract was subjected to a specific RIA for human AM (hAM) as previously reported $(7,8)$. The cross-reactivities of the anti-hAM antiserum used in this RIA were $100 \%$ with hAM with a C-terminal carboxyl structure (hAM$\mathrm{COOH}), 100 \%$ with hAM(1-51)-COOH and less than $0.5 \%$ with hAM(13-52). The intra- and inter-assay coefficients of variation for this assay were $5.0 \%$ and $4.8 \%$, respectively. The plasma ANP and BNP concentrations were measured with specific immunoradiometric assays for human ANP and BNP, respectively (ShionoRIA ANP and BNP kits, Shionogi \& Co., Ltd., Osaka, Japan). The accuracies as well as the detailed methods of these assays have been described previously $(8,9)$.

\section{Statistical Analysis}

All data were stored and analyzed using SPSS software version 8.0 (SPSS Inc., Chicago, USA). Linear regression analysis was used to assess the relationships between the two variables. Multiple linear regression was carried out to determine the independence of association with other variables. The data are presented as the means $\pm \mathrm{SD}$, and values of $p<0.05$ were considered to indicate statistical significance.

\section{Results}

\section{Basal Measurements and Plasma Concentrations of AM, ANP and BNP}

Table 1 shows the basal profiles of the subjects examined in this study. According to the criteria shown in this table, $30 \%$, $29 \%$ and $17 \%$ of them were found to have hypertension, obesity and hypercholesterolemia, respectively, but the serum creatinine levels of all the subjects were within normal limits. The mean values of the AM, ANP and BNP concentrations were $6.59 \pm 1.38,4.91 \pm 2.74$, and $4.59 \pm 4.09$ $\mathrm{fmol} / \mathrm{ml}$, respectively.

\section{Correlations by Univariate Analyses}

We first analyzed the data by univariate analysis to examine the relationships between the plasma levels of the hypotensive peptides and the other parameters of age, systolic and diastolic blood pressure (SBP and DBP), pulse pressure (PP), body mass index (BMI), serum total cholesterol and creatinine. As shown in Fig. 1, the plasma levels of AM, ANP and BNP were all significantly correlated with age; in 

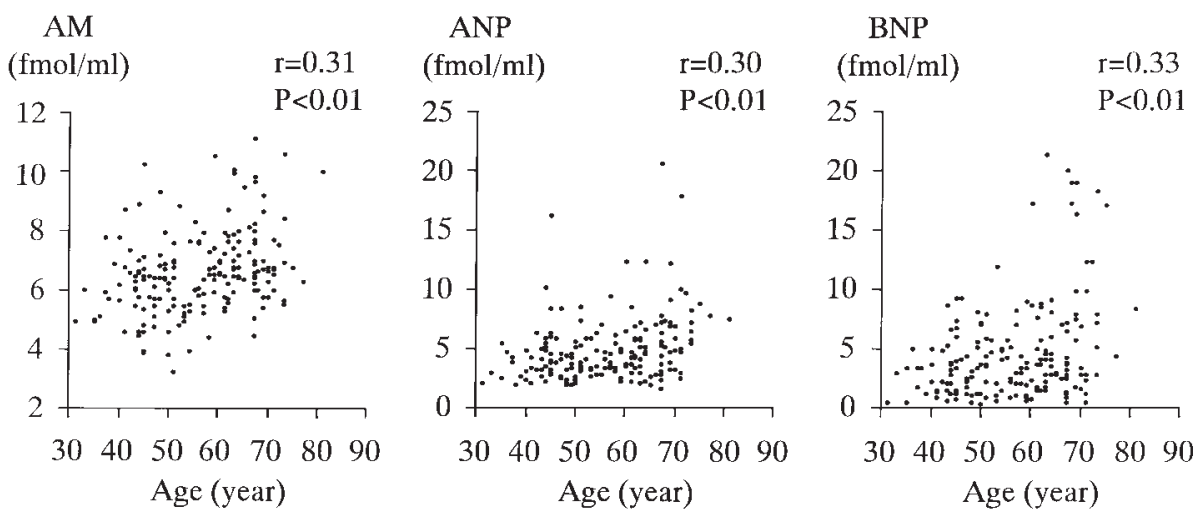

Fig. 1. Relationships between age and plasma levels of $A M, A N P$ and BNP.
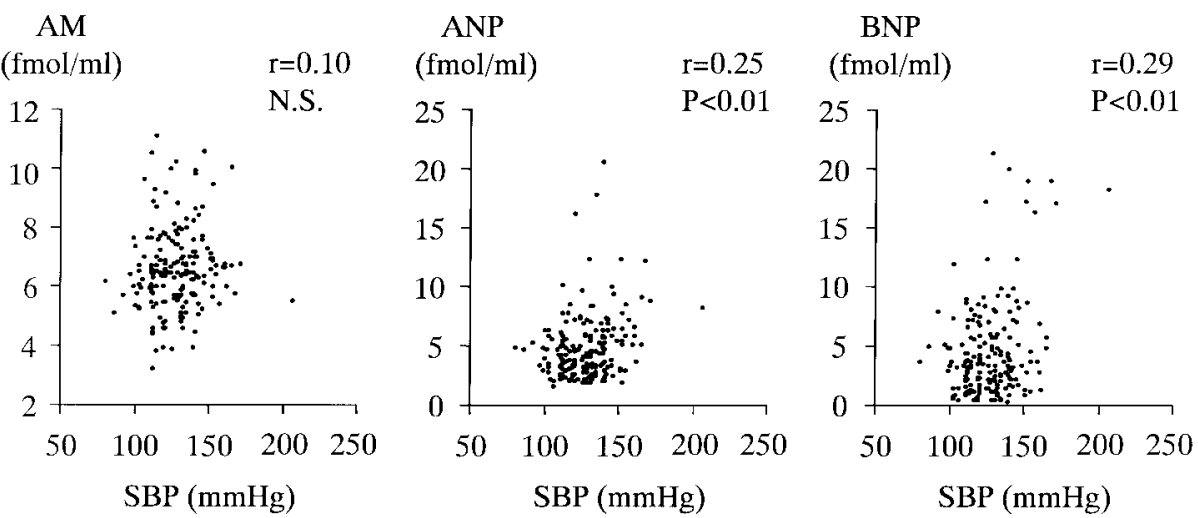

Fig. 2. Relationships between systolic blood pressure (SBP) and plasma levels of AM, ANP and BNP. N.S., not significant.
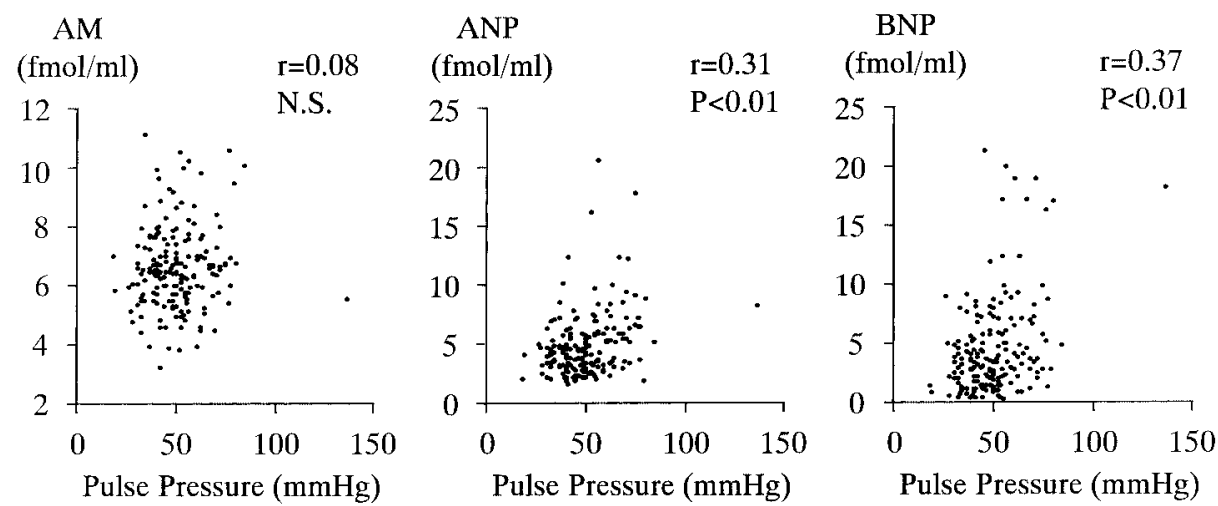

Fig. 3. Relationships between pulse pressure and plasma levels of AM, ANP and BNP. N.S., not significant.

addition, the plasma levels of ANP and BNP were significantly related to SBP and PP (Figs. 2 and 3). Interestingly, a significant correlation was found between the plasma AM level and BMI (Fig. 4). A weak correlation was also found between the plasma AM and serum creatinine level $(r=0.18$, $p<0.05)$. As expected, an intimate relationship was found between the plasma levels of ANP and BNP (Fig. 4), while the plasma AM level was not correlated with either natriuret- ic peptide level.

\section{Multivariate Analysis Using a Stepwise Method}

We further examined the relationships by multivariate analysis using a stepwise method, in which the plasma levels of $\mathrm{AM}, \mathrm{ANP}$ and BNP were used as dependent variables and the age, gender, SBP, DBP, PP, BMI, serum total cholesterol 

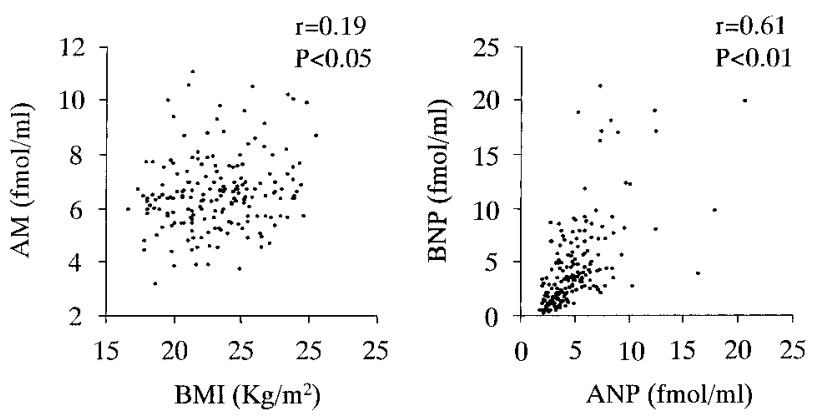

Fig. 4. Relationships between plasma levels of AM and BMI (left) and between plasma levels of ANP and BNP (right).

and creatinine were used as independent variables. As shown in Table 2, similar to the results of the univariate analysis, age was found to be a significant, independent variable for the plasma levels of each of AM, ANP and BNP, and PP was independently significant for the latter two natriuretic peptides. In addition, the BMI and gender were significant factors for the plasma levels of AM and BNP, respectively.

\section{Discussion}

AM, ANP and BNP are blood pressure-lowering peptides possessing vasodilator and natriuretic properties (2-5). Previous reports have shown that the plasma concentrations of these peptides in patients with hypertension or congestive heart failure were higher than those of control subjects, suggesting their roles in counteracting elevation of blood pressure and fluid retention (2-6). Previous studies have also reported that plasma ANP and BNP are elevated by aging in humans $(10,11)$, and our present observations are in accord with this; however, there has been no report on the age-related change of plasma AM. In the present study, we found that plasma AM increased with age in local residents without overt cardiovascular disease. The multivariate analysis showed that this age-related increase was independent of the parameters reported to be closely associated with the plasma AM levels, such as blood pressure or serum creatinine levels $(2,3,6)$. In the present study, the female residents had a higher plasma BNP level than the males, a finding consistent with the previous study (12), while the plasma AM was found to be independent of gender.

Both ANP and BNP are peptide hormones secreted from the heart $(4,5)$. ANP is secreted from the cardiac atria in response to increased atrial pressure or atrial stretching, while BNP is produced mainly in the cardiac ventricles, and either increased preload or afterload to the heart results in an increased secretion of BNP $(4,5)$. Reduced diastolic function of the cardiac ventricle with aging (13), which results in an increased left atrial pressure or atrial stretching, may stimulate ANP secretion from the left atrium. Sayama et al. reported that the age-related increase in the left ventricular
Table 2. Multivariate Analyses of Stepwise Method

\begin{tabular}{lllr}
\hline $\begin{array}{c}\text { Dependent } \\
\text { variable }\end{array}$ & $\begin{array}{c}\text { Independent } \\
\text { variable }\end{array}$ & $\beta$ & $p$ value \\
\hline AM & Age & 0.306 & $<0.001$ \\
& BMI & 0.180 & 0.010 \\
ANP & PP & 0.234 & 0.002 \\
& Age & 0.225 & 0.002 \\
BNP & Age & 0.265 & $<0.001$ \\
& PP & 0.264 & $<0.001$ \\
& Gender & 0.157 & 0.021 \\
\hline
\end{tabular}

Independent variables included are age, gender (male $=1$, female $=$ 2), systolic and diastolic blood pressure, pulse pressure (PP), serum creatinine, total cholesterol and body mass index (BMI).

mass index is closely associated with the increased plasma BNP level in elderly subjects, suggesting an increased BNP secretion from the hypertrophied left ventricle (14). Since many of the peptide hormones are metabolized by the kidneys, the age-related reduction in renal function may be another factor (15). In addition to clearance by the kidneys, Giannessi et al. recently found that the number of "clearance" receptors (C-receptors) for natriuretic peptides was lower in the platelets of elderly subjects than in the platelets of younger subjects (16). Thus, a number of mechanisms may be involved in the age-related increase in plasma ANP and BNP levels.

It has been shown that AM is produced in various organs and tissues, including the vascular wall and myocardium (2, 3). Sumitomo et al. reported that the plasma AM levels in patients with hypertension complicated by cardiac hypertrophy were higher than those in hypertensive patients without cardiac hypertrophy (17). Kohno et al. reported that increased AM levels in hypertensive patients are closely associated with impaired renal function (18). As proposed for the plasma ANP and BNP levels, either an increased production or a decreased clearance rate of AM may account for the age-related increase in plasma AM. In addition to age, we found that BMI is an independent factor for the plasma levels of AM. AM was found to be secreted from the vascular endothelial and smooth muscle cells, and the secretion was shown to be stimulated by oxidized low density lipoprotein (LDL) and lysophosphatidylcholine or by culturing with high glucose media $(19,20)$. In accord with the high glucose-stimulated AM secretion, Hayashi et al. reported that the plasma levels of AM increased in patients with diabetes mellitus (21). Thus, the relationship between plasma AM and BMI suggests that the plasma level of AM may reflect a metabolic disorder of glucose or lipids, which would affect $\mathrm{AM}$ production in the vasculature of subjects with higher BMI. In our preliminary observation, we detected AM immunoreactivity in rat adipose tissue, although few data are currently available regarding AM production in human fat tissue. We may also need to take this possibility into account 
to interpret the relationship between the plasma AM and BMI. In any case, the detailed mechanism remains to be clarified and further studies should be carried out to test these hypotheses.

An increase in PP, a parameter obtained simply by subtracting DBP from SBP, has recently been recognized as an independent risk factor of cardiovascular disease $(22,23)$. Interestingly, in the present study, we found that both the plasma ANP and BNP levels were closely related with PP not only by univariate but also by multivariate analyses. An increased stiffness of the great vessels is known to be an important factor affecting the PP value $(22,23)$. Reduced compliance of the vessels leads to an increase in SBP and a decrease in DBP, resulting in an increased PP. There have been a number of reports showing that cardiac hypertrophy is closely correlated with the degree of arterial stiffness or with PP in patients with hypertension (24-26). Recently, Zakopoulos et al. found a close association between the left ventricular mass and PP determined by ambulatory blood pressure monitoring, even in subjects without hypertension (27).

As discussed above, cardiac hypertrophy with left ventricular diastolic dysfunction seems to be an important factor closely related to the increased plasma levels of ANP and BNP. The intimate relationships between PP and the plasma levels of ANP and BNP suggest that these natriuretic peptide levels are markers for either cardiac hypertrophy or left ventricular diastolic dysfunction closely associated with stiffness of the great vessels. Meanwhile, the AM level was significantly correlated with age, but not with SBP or PP. Moreover, we found no significant correlation between the plasma $\mathrm{AM}$ and natriuretic peptide levels in spite of the similar elevation by aging and the intimate relationship between the ANP and BNP levels. These differential hormonal aspects of $\mathrm{AM}$ may reflect the fact that AM is produced in various organs and tissues while ANP and BNP are produced mainly in the heart $(2-5)$

\section{Acknowledgements}

We thank Ms. Mari Yanagida for her technical assistance in the AM, ANP and BNP assays.

\section{References}

1. Kitamura K, Kangawa K, Kawamoto M, et al: Adrenomedullin: a novel hypotensive peptide isolated from human pheochromocytoma. Biochem Biophys Res Commun 1993; 192: 553-560.

2. Kitamura K, Eto T: Adrenomedullin-physiological regulator of the cardiovascular system or biochemical curiosity? Curr Opin Nephrol Hypertens 1997; 6: 80-87.

3. Eto T, Kitamura K, Kato J: Biological and clinical roles of adrenomedullin in circulation control and cardiovascular diseases. Clin Exp Pharmacol Physiol 1999; 26: 371-380.

4. Needleman P, Braine EH, Greenwald JE, et al: The bio- chemical pharmacology of atrial peptides. Annu Rev Pharmacol Toxicol 1989; 29: 23-54.

5. Levin ER, Gardner DG, Samson WK: Natriuretic peptides. N Engl J Med 1998; 339: 321-328.

6. Kuriyama S, Kobayashi H, Tomonari H, et al: Circulating adrenomedullin in erythropoietin-induced hypertension. Hypertens Res 2000; 23: 427-432.

7. Kitamura K, Ichiki Y, Tanaka M, et al: Immunoreactive adrenomedullin in human plasma. FEBS Lett 1994; 341: 288-290.

8. Kato J, Kitamura K, Matsui E, et al: Plasma adrenomedullin and natriuretic peptides in patients with essential or malignant hypertension. Hypertens Res 1999; 22: 61-65.

9. Yasue H, Yoshimura M, Sumida H, et al: Localization and mechanism of secretion of B-type natriuretic peptide in comparison with those of A-type natriuretic peptide in normal subjects and patients with heart failure. Circulation 1994; 90: 195-203.

10. Ohashi M, Fujio N, Nawata H, et al: High plasma concentrations of human atrial natriuretic polypeptide in aged men. J Clin Endocrinol Metab 1987; 64: 81-85.

11. Wallen T, Landahl S, Hedner T, Saito Y, Masuda I, Nakao $\mathrm{K}$ : Brain natriuretic peptide in an elderly population. $J$ Intern Med 1997; 242: 307-311.

12. Lunchner A, Burnett JC Jr, Jougasaki M, et al: Evaluation of brain natriuretic peptide as marker of left ventricular dysfunction and hypertrophy in the population. $J$ Hypertens 2000; 18: 1121-1128.

13. Klein AL, Burstow DJ, Tajik AJ, Zachariah PK, Bailey KR, Seward JB: Effects of age on left ventricular dimensions and filling dynamics in 117 normal persons. Mayo Clin Proc 1994; 69: 212-224.

14. Sayama H, Nakamura Y, Saito N, Kinoshita M, Suda M: Relationship between left ventricular geometry and brain natriuretic peptide levels in elderly subjects. Gerontology 2000; 46: 71-77.

15. Papper S: The effects of age in reducing renal function. Geriatrics 1973; 28: 83-87.

16. Giannessi D, Andreassi MG, Del Ry S, Clerico A, Colombo MG, Dini N: Possibility of age regulation of the natriuretic peptide C-receptor in human platelets. $J$ Endocrinol Invest 2001; 24: 8-16.

17. Sumitomo $\mathrm{T}$, Nishikimi $\mathrm{T}$, Mukai M, et al: Plasma adrenomedullin concentrations and cardiac and arterial hypertrophy in hypertension. Hypertension 1997; 30: 741-745.

18. Kohno M, Hanehira T, Kano H, et al: Plasma adrenomedullin concentrations in essential hypertension. Hypertension 1996; 27: 102-107.

19. Isumi Y, Shoji H, Sugo S, et al: Regulation of adrenomedullin production in rat endothelial cells. Endocrinology 1998; 139: 838-846.

20. Hayashi M, Shimosawa T, Fujita T: Hyperglycemia increases vascular adrenomedullin expression. Biochem Biophys Res Commun 1999; 258: 453-456.

21. Hayashi M, Shimosawa T, Isaka M, Yamada S, Fujita R, Fujita T: Plasma adrenomedullin in diabetes. Lancet 1997; 350: $1449-1450$.

22. Smulyan H, Safar ME: The diastolic blood pressure in systolic hypertension. Ann Intern Med 2000; 132: 233-237.

23. Millar JA, Lever AF, Burke V: Pulse pressure as a risk fac- 
tor for cardiovascular events in the MRC Mild Hypertension Trial. J Hypertens 1999; 17: 1065-1072.

24. Bouthier JD, De Luca N, Safar ME, Simon AC: Cardiac hypertrophy and arterial distensibility in essential hypertension. Am Heart J 1985; 109: 1345-1352.

25. Brahimi M, Dahan M, Dabire H, Levy BI: Impact of pulse pressure on degree of cardiac hypertrophy in patients with chronic uraemia. J Hypertens 2000; 18; 1645-1650.

26. Roman MJ, Ganau A, Saba PS, Pini R, Pickering TG, Devereux RB: Impact of arterial stiffening on left ventricular structure. Hypertension 2000; 36: 489-494.

27. Zakopoulos NA, Lekakis JP, Papamichael CM, et al: Pulse pressure in normotensives: a marker of cardiovascular disease. Am J Hypertens 2001; 14: 195-199. 